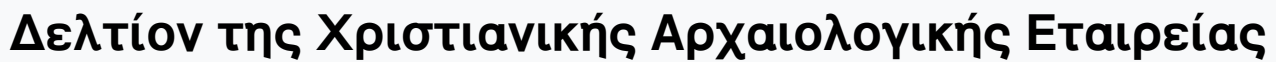

Tóp. 4 (1904)

$\Delta \varepsilon \lambda$ tíov XAE 4 (1904), Пврíodoc A'

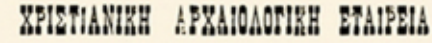

YחO THM กFOETAEIAN

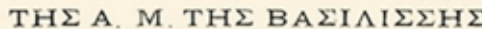

\section{$\Delta \mathrm{E} \Lambda \mathrm{TION} \Delta^{\mathrm{ON}}$}

П EPIEXON

TA $\Sigma$ EPГA $\Sigma$ IA $\Sigma$ TH $\Sigma$ ETAIPEIA $\Sigma$

ETIMEAEIA

г. $\triangle A M \Pi A K H$

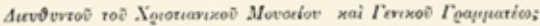

rîs 'Erapeia;

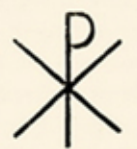

EN $A \theta H N A I 2$

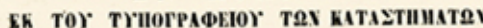

zOYPIASOE Korzersiser

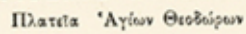

$$
1904
$$

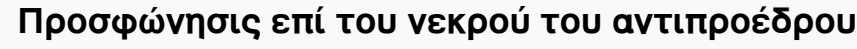

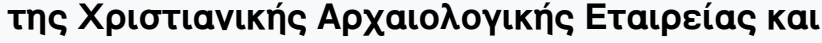

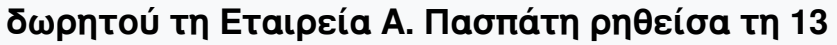

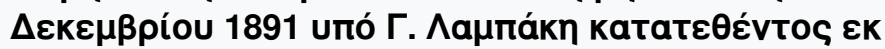

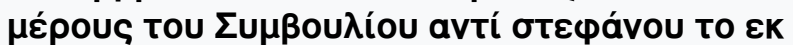

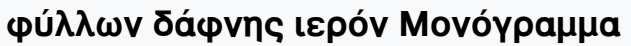

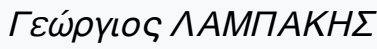

doi: $\underline{10.12681 / \text { dchae. } 1579}$ 


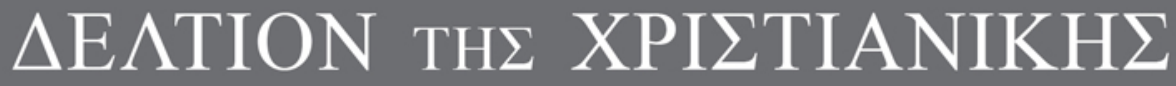 APXAIO $\Lambda$ OГIKH $\Sigma$ ETAIPEIA $\Sigma$}

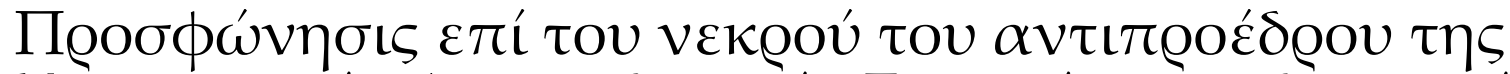

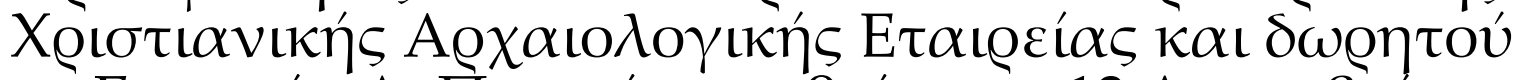

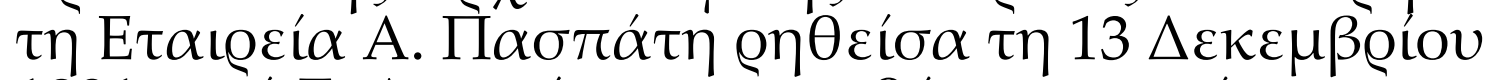

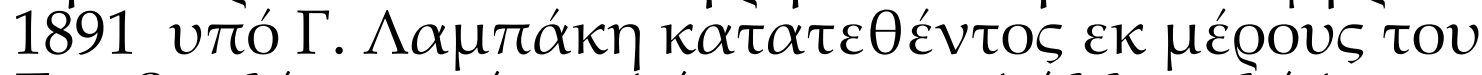

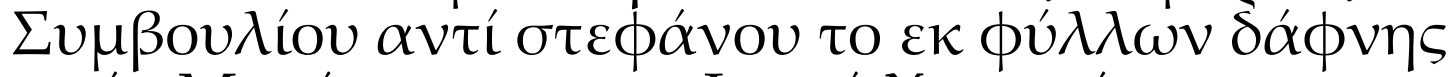

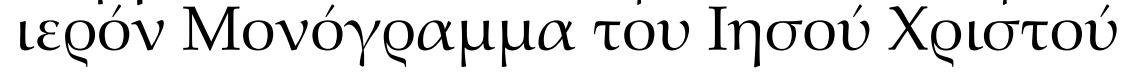

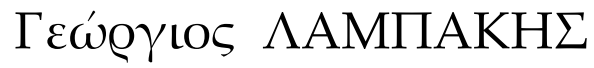

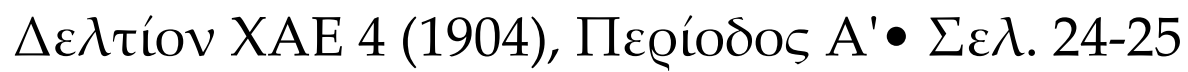

\section{A@HNA 1904}




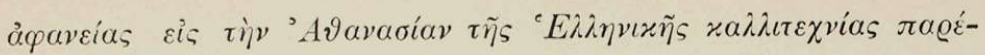

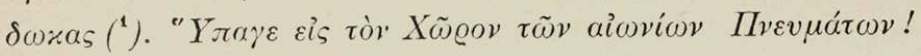

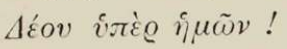

\section{P $0 \Sigma \Phi \Omega N H \Sigma I \Sigma$}

\section{EIII TOY NEKPO Y}

TOY ANTITPOEDPOY THE XPISTIANIKHE APXAIONOTIKH

ETAIPEIA $\Sigma$ KAI $\triangle \Omega$ PHTOY TH, ETAIPEIA.

\section{A. $\Pi A \Sigma \Pi A T H$}

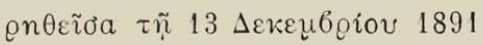

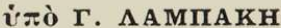

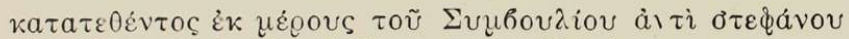

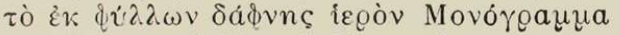

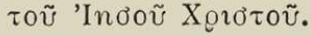

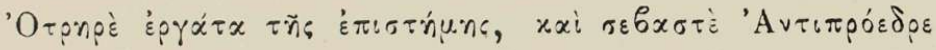

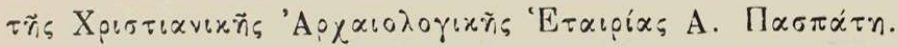

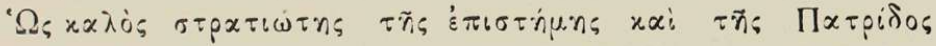

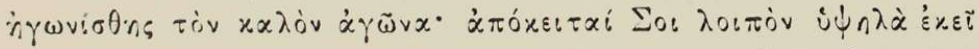

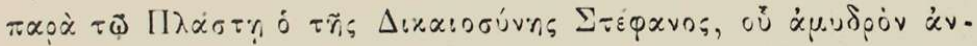

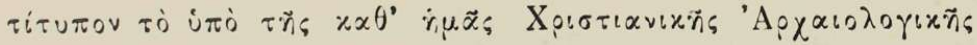

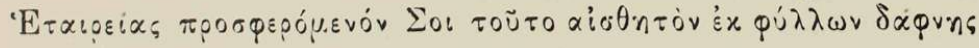
бư

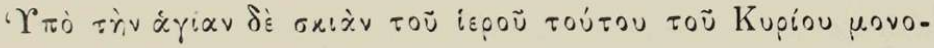

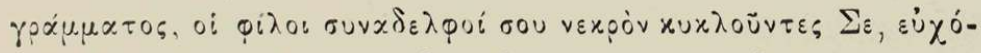

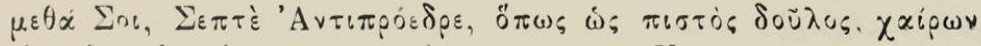

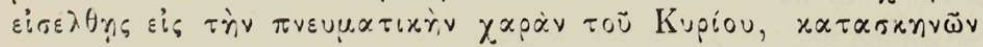

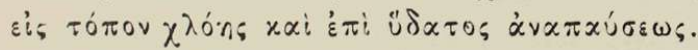

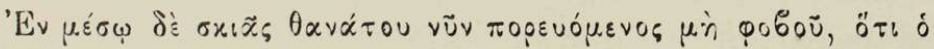

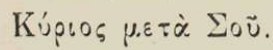

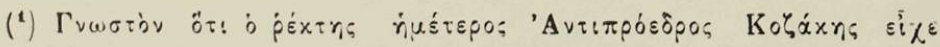

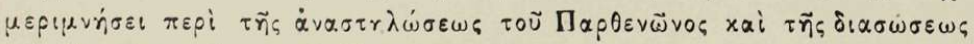

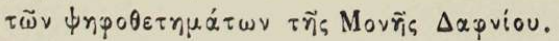




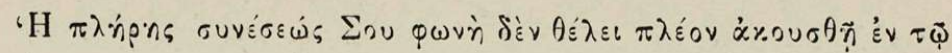

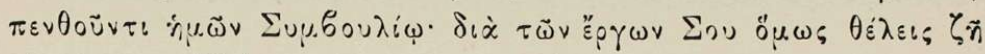

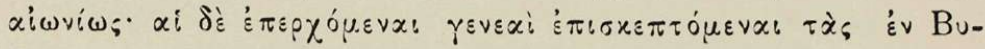

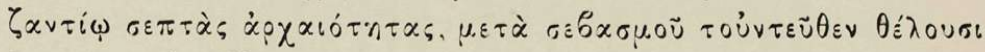

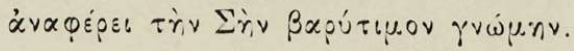

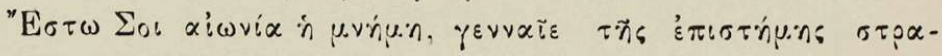

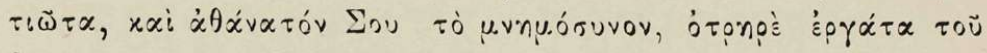
$\dot{\alpha} u \pi \varepsilon \lambda \tilde{\omega}$ vos $\tau 0 \tilde{U}$ Kupíou.

\section{P $0 \Sigma \Phi \Omega N H \Sigma I \Sigma$}

\section{EIII TOY NEKPOY}

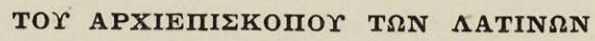

I. MAPATKOY

\section{WIITIMOY NEAOY KAI ASPHTOY TH, ETAIPEIA,}

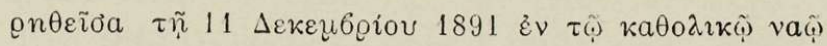

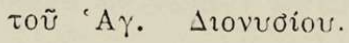

$$
\text { úं̇̀ } \Gamma \text {. ААMாAKH }
$$

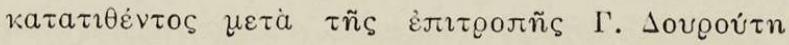

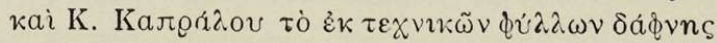

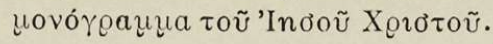

\section{Reverentissime episcope Christi.}

Christiana Archaeologica Societas. Tibi, a I Aeternam Civitatem Dei eunti,hanc Coronam sancti monogram. matis Ejus qui dixit . credens in ME etiam si mortuus fuerit vivet o offert.

Requiesce in pace

$$
\begin{aligned}
& \text { Episcope Christi } \\
& \text { Pastor Christi } \\
& \text { Miles Cristi. Amen. }
\end{aligned}
$$

Anno Dni vucccxci 1891 mensis decembris. Die xı. 